\title{
Kernos
}

Revue internationale et pluridisciplinaire de religion grecque antique

9| 1996

Varia

\section{Revue des actes de colloques}

\section{(2) OpenEdition \\ Journals}

\section{Édition électronique}

URL : http://journals.openedition.org/kernos/1209

DOI : 10.4000/kernos.1209

ISSN : 2034-7871

\section{Éditeur}

Centre international d'étude de la religion grecque antique

\section{Édition imprimée}

Date de publication : 1 janvier 1996

ISSN : 0776-3824

\section{Référence électronique}

«Revue des actes de colloques », Kernos [En ligne], 9 | 1996, mis en ligne le 21 avril 2011, consulté le 24 septembre 2020. URL : http://journals.openedition.org/kernos/1209 ; DOI : https://doi.org/ 10.4000/kernos. 1209 
malheureusement, était sorti de quelques mois à peine qu'Ugo Bianchi décédait à Rome, laissant indubitablement un grand vide, mais aussi une foule d'élèves et disciples qui auront à coeur, comme Giulia Sfameni Gasparro, l'éditrice de ce volume, de reprendre le flambeau.

\section{Actes de colloques}

\section{VV. AA., Actas del VIII Congreso Español de Estudios Cläsicos (Madrid, 23 al 28 de septiembre de 1991), Eds. Clásicas, Madrid, 1994 (3 vols).}

Vol. II :

Emilio SUÁREZ DE LA TORRE, Religión griega y lírica arcalca, p. 33-79

Eduardo ACOSTA MÉNDEZ, Sócrates, Aristón estoico y Filodemo: sobre la percepción de la divinidad, p. 83-89

Alberto BERNABÉ PAJARES, Consideraciones sobre una Teogonía órfica, p. 91-100

Francesco CASADESÚs BORDOY, Heródoto II 81: ¿Orficos o pitagóricos?, p. 107-111

Paul DEMONT, Le Protagoras de Platon, Hérodote et la providence, p. 145-158

M. Regla FERNÁNDEZ GARRIDO, Ammonio de Alejandria y el cristianismo, p. 173-180

José GARCía LOPEZ, Tipología religiosa en las Vidas de Plutarco: Teseo, p. 187-193

José María LUCAS DE DIOS, El motivo de Puttfar en la tragedia griega, p. 259-262

Aurelio PÉREZ JIMÉNEZ, Etra, la visión de la madre a través del béroe, p. 307-313

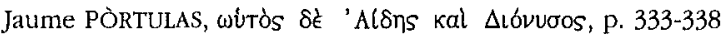

Angel RUIZ PÉREZ, Oráculo y profecia en Estesicoro, p. 403-408

María del Henar VELASCO LóPEZ, La förmula de petición del agua en las lâminas órficas, p. $455-460$.

Vol. III :

Rosa María Agullar FERNÁNDEZ, Los dioses de Solón, p. 69-76

María del Carmen BARRigón FUENTES, Los dioses en Simónides de Ceos, p. 77-84

Inés Calero SECALL, Las detdades femeninas en las Posthoméricas de Quinto de Esmima, p. $91-98$

César FORNís VAQUERO, El papel del oráculo de Delfos en la tiranía arcaica, p. 145-152

Luis A. GARCIA MORENO, El mito de Gerión. Una nueva bipótesis de su origen a la manera de Sir James, p. 153-159

Oscar GARCIA SANZ, Efectos del alcobol sobre el culto, p. 169-173

María Paz de HOZ GARCÍA-BELLiDO, Cultos lidios en época belenística e imperial, p. 203-212 María LUz PRIETO PRIETO, Ares en el mundo de la magia, p. 267-273

Juan SIMÓN PALMER, Demonología en el Pratum spirituale de Juan Mosco, p. 303-308

Margarita VALLEJO GIRVÉS, Testimonios literarios sobre prácticas paganas en el África bizantina, p. 309-316.

Jaime Alvar, Carmen Blánquez, Carlos G. Wagner (éds), Sexo, Muerte y Religión en el Mundo clásico. Tercer encuentro-coloquio de ARYS. Jarandilla de la Vera. Diciembre 1991, Ediciones Clásicas, Madrid, 1994, 271 p.

Domingo PLÁCIDO, Los celos de Deyanira, p. 11-16

María José RODRÍGUEZ MAMPASO, Los paisajes reflejados: Pandora, p. 17-27

Arminda LOZANO, Las komyria: unas fiestas religlosas reservadas a los bombres, p. 29-41 
Manuel GUERRA GómEz, La condición sagrada (tabui) de la vida y su fuente: la sexualidad en las religiones y en las "ideologías" belénicas, p. 43-70

Miguel Ángel VINAGRE LOBO, Serapts y los libros de sueños, p. 125-134

Jaime ALVAR, Muerte de amor divino. Atts, p. 145-156

Rebeca RUBIO RIVERA, Los isiacos y su mundo funerario, p. 157-169.

Diana Buitron-Oliver (éd.), New Perspectives in Early Greek Art, Washington, National Gallery of Art, 1991, 308 p., nbr. ill. (Studies in the History of Art, 32. Center for Advanced Study in the Visual Arts. Symposium Papers XVI).

Walter BURKERT, Homer's Antbropomorphism: Narrative and Ritual, p. 81-91

Emily VERMEULE, Myth and Tradition from Mycenae to Homer, p. 99-121, 48 fig.

H.A. SHAPIRO, Theseus: Aspects of the Hero in Archaic Greece, p. 123-139, 20 fig.

Bernard C. DIETRICH, Aegean Sanctuaries: Forms and Function, p. 141-149

Richard V. NICHOLLS, Early Monumental Religious Arcbitecture at Old Smyma, p. 151-171, 17 fig.

Vassilis LAMBRINOUDAKIS, The Sanctuary of Iria on Naxos and the Birth of Monumental Greek Arcbitecture, p. 173-188, 19 fig.

Olga TZAHOU-ALEXANDRI, $A$ Vase-Painter as Dedicator on the Atbenian Acropolis: $A$ New View of the Painter of Acropolls 606, p, 191-214, 24 fig.

René Ginouvès, Anne-Marie GuIMIER-SORbiER, Jacques JoUANNA, Laurence VILLARD (éds), L'eau, la santé et la maladie dans le monde grec. Actes du colloque organisé à Paris (CNRS et Fondation Singer Polignac) du 25 au 27 novembre 1992, École française d'Athènes (diffusion de Boccard), 1994, XI+399 p., nbr. ill. (BCH Supplément 28).

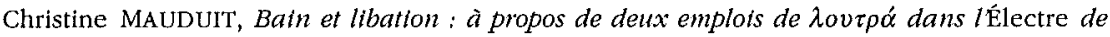
Sopbocle, p. 131-146

Vinciane PIRENNE-DELFORGE, La loutropborte et la "prêtresse-loutropbore " de Sicyone, p. $147-155$

Véronique BOUDON, Le rôle de l'eau dans les prescriptions médicales d'Asclépios cbez Galien et Alitis Aristide, p. $157-168$

Pierre AUPERT, L'eau curative à Argos, p. 193-200, 4 fig.

Yvette MORIzOT, Artémis, l'eau et la vie bumaine, p. 201-216, 7 fig.

Lilly KAHIL, Bains de statues et de divinités, p. 217-223

Vassili LAMBRINOUDAKIS, L'eau médicale à Épidaue, p. 225-236, 9 fig.

Renè GINOUVÈs, L'eau dans les sanctuaires médicaux; p. 237-246, 3 fig.

\section{Colette Jourdain-Annequin, Corinne Bonnet (éds), IIe Rencontre} Héracléenne. Héraclès, les femmes et le féminin. Actes du Colloque de Grenoble. Université des Sciences Sociales (Grenoble II), 22-23 octobre 1992, Bruxelles-Rome, Brepols, 1996, 291 p. (Institut Historique Belge de Rome. Études de Philologie, d'Archéologie et d'Histoire Anciennes, 31). ISBN : 90-74461-12-3.

Nicole LORAUX, Avant-propos, Et toujours Héraclès passe, p. 7-17

Bernard SERGENT, Ces demoiselles de Stympbale, p. 19-34

Pierre BRULÉ, Héraclès et Augé. À propos des ortgines rituelles du mytbe, p. 35-50

Didier PRALON, Héraclès et Iole, p. 51-76

Françoise LÉTOUBLON, Héraclès et les Thespiades, p. 77-87

Stefan RITTER, Ercole e Onfale nell'arte romana dell'età tardo-repubblicana e augustea, p. $89-102$ 
F. WULF ALONSO, L'bistoire d'Omphalè et d'Héraklès, p. 103-120

Corinne BONNET, Héraclès travesti, p. 121-131

Paolo SCARPI, Héraclès. Trop de mets, trop de femmes, p. 133-143

Françoise BADER, Héraklès, Ogmios et les Strènes, p. 145-185

Lorenzo BRACCESI, Le fidanzate di Eracle, p. 187-194

Nicola CUSUMANO, Eracle e l'elemento femminile in Sicilia. Per un modello interpretativo delle forme di contatto tra indigent e colonizzatori nella Sicilia greca, p. 195-214

Maurizio Giangiulio, Le béros fondateur, l'espace sacré de la déesse. Notes sur Héraclès et les sanctuaires d'Héra du Péloponnèse à la Grande Grèce, p. 215-233

Anne-France LAURENS, Héraclès et Hébé dans la céramique grecque ou les noces entre terre et ciel, p. 235-258, 14 fig.

Claudine LEDUC, Atbéna et Héraklès : une parenté botanique?, p. 259-266, 1 fig.

Colette JOURDAIN-ANNEQUIN, Héraclès et les divinités féminines, p. 267-289, 2 fig.

Juan Antonio López Férez (éd.), De Homero a Libanio, Madrid, 1995, VIII + 402 p. (Estudios actuales sobre textos griegos, II)

Emilio SUÁREZ DE LA TORRE, Observaciones sobre el Oráculo délfico no 1 Parke-Wormell (178 Hendess, $Q 26$ Fontenrose, 1 Andersen), p. 9-24

Carles MiRALlez, Dioniso tal como es presentado por Tirestas. Euripides, Bacantes 266$326, \mathrm{p}, 163-82$

Alberto BERNABÉ, Una cosmogonía cómica: Aristófanes, Aves 685 ss., p. 195-211

Manuel GARCÍA TEuJEIRO, Sobre una defixtón ática: $1 G$ IIL/3 no 97, p. 317-328

Gaspar MOROCHO, Exégesis de un mito oriental en Dión de Prusa: Or. XXXVI 39-47, p. 345364.

Jesús M. a NIETo IBÁÑ̃z (coord.), Estudios de religion y mito en Grecia y Roma. X Jornadas de Filología Clásica de Castilla y León, León, Universidad, Secretariado de Publicaciones, 1995, 295 p., ill.

Emilio SUÁREZ DE LA TORRE, La función del mito en la religión griega, p. 15-35

Purificación NIETO HeRNÁNDEZ, Mensajeros divinos en Homero: Iris y Hermes en la Ilíada y en la Odisesa, p. 37-52

Jesús-María NIETO IBÁÑEZ, Troya y Sícimos: La épica homérica de Teódoto el judío, p. 5357

Máximo BRIOSO SÁNCHEZ, Poesía y rellglón en la antigtledad griega tardia, p. 59-87

$M^{a}$ Carmen BARRIGÓN FUENTES, La utilización del mito en la obra de Artemidoro, p. 89-101

Gaspar MOROCHO GAYO, Mito Griego y Literatura Cristiana: Los Reyes Magos, p. 103-122

Manuel-Antonio MARCOS CASQUERO, Creencias religioso-supersticiosas del mundo antiguo relativas al cabello, p. 123-153

$M^{a}$ Asunción SÁNCHEZ MANZANO, Venus grata, p. 155-163

$\mathrm{M}^{a}$ Jesús PÉREZ IBÁÑEZ, Mito y textos médicos renacentistas, p. 207-219

Beatriz ANTÓN MARTÍNEZ, La mitología en la literatura emblemática del Siglo de Oro: Los Emblemata centum regio-política de J. de Solorzano, p. 221-236

José María BALCELLS, La mitología en la Epopeya paródica del siglo XVII, p. 237-246

Antonio Ma MARTín RODRíguez, Paralelos folclóricos en la figura de Aquiles, p. 247-257

Begoña ORTEGA VILLARO, El mito de Fedra y su transfomación en tema literario, p. 259271

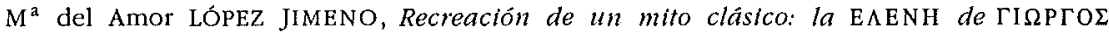

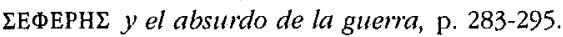


Attilio MASTrocinque (éd.), Ercole in Occidente, Trento, Dipartimento di Scienze Filologiche e Storiche, 1993, 117 p. (Labirinti, 2)

Maurizio GIANGIULIO, La dedica ad Eracle di Nicomaco (IG. XIV 652), p. 29-48, 4 fig.

Attilio MASTROCINQUE, Eracle "Iperboreo" in Italia, p. 49-61, 10 fig.

Domingo PLÁCIDO, Le vie di Ercole nell'estremo Occidente, p. 63-80, 6 fig.

Mariette DE VOS, Eracle e Priamo. Trasmissione di potere: mitología e ideologia imperiale, p. $81-89,16$ fig.

Mario TORELLI, Gli aromi e il sale. Afrodite ed Eracle nell'emporia arcaica dell'ttalia, p. 91-117, 6 fig.

Franca Maria VANNI, L'iconografia di Ercole nelle monete di zecca africana, p. 119-123, 8 fig.

Attilio MASTROCinQue (éd.), I grandi santuari della Grecia e l'Occidente, Trento, Dipartimento di Scienze Filologiche e Storiche, 1993, 158 p. (Labirinti, 3)

Antonio ALONI, Introduzione: l'invenzione di Delo, p. 13-30

Filippo COARELL, I Tarquini e Delfi, p. 31-42

Giovanni COLONNA, Doni di Etruschi e di altri barbari occidentali nei santuari panellenici, p. $43-67,15$ fig.

Juliette DE LA GENIÈRE, L'mizio della romanizzazione a Claros, p. 69-79, 2 fig.

Mariette DE VOS, Il tempio di Iside in via Labicana a Roma, p. 81-91, 6 fig.

Maurizio GIANGIULIO, Le città di Magna Grecia e Olimpia In età arcaica, p. 93-118

Attilio MASTROCINQUE, Artisti samii in Occidente, p. 119-135, 6 fig.

Ulrich SINN, L'attività dell'imperatore Nerone ad Olimpia. Risultati e prospettiva dei nuovi scavi, p. 137-147

Marta SORDI, I rapporti fra Roma e Delfi e la decima, p. 149-158.

Jon Solomon (éd.), Apollo. Origins and Influences, Tucson-London, The University of Arizona Press, 1994, XII + 196 p.

Gregory NAGY, The Name of Apollo: Etymology and Essence, p. 3-7

Darice BIRGE, Sacred Groves and the Nature of Apollo, p. 9-19

Jenny STRAUSS CLAY, Tendenz and Olympian Propaganda in the Homeric Hymn to Apollo, p. $23-36$

Jon SOLOMON, Apollo and the Lyre, p. 37-46

Walter BURKERT, Olbia and Apollo of Didyma: A New Oracle Text, p. 49-60

T.H. CARPENTER, The Terrible Twins in Sixtb Century Attic Art, p. 61-79, 8 fig.

Anton BIERL, Apollo in Greek Tragedy: Orestes and the God of Initiation, p. 81-96

John F. MILLER, Virgll, Apollo, and Augustus, p. 99-112

Frederick AHL, Apollo: Cult and Prophesy in Ovid, Lucan, and Statius, p. 113-134.

\section{Ouvrages collectifs et mélanges}

\section{Rosa María Aguilar, Mercedes López Salvá, Ignacio Rodríguez Alfageme (éds), XAPI $\Sigma$ II $\triangle A \Sigma K A \Lambda I A \Sigma$ Homenaje a Luis Gil, Editorial Complutense, Madrid, 1994, 837 p. (Studia in honorem Ludovici Aegidii).}

Martín RUIPÉREZ SÁNCHEZ, Edipo y los curanderos míticos, p. 231-240

Emilio SUÁREZ DE LA TORRE, El adivino Poliido, p. 243-267

José GARCÍA LÓPEz, Concepción MORALES OTAL, El Agamenón de Esqullo: escenificación de un sacrificio, p. 271-278 